Open Access

\title{
"In vitro comparison of the adsorption of inflammatory mediators by blood purification devices": a misleading article for clinical practice?
}

Marco Feri ${ }^{*}$ (D)

\section{To the Editor,}

I find this article from Malard et al. very interesting, since it aims to analyze the effect of three blood purification devices-CytoSorb, Toraymyxin, and oXiris-in removing toxic molecules involved in septic shock [1]. However, the study shows some limitations that could lead to the incorrect clinical use of these sorbents.

The experiments were performed for $2 \mathrm{~h}$ using $500 \mathrm{ml}$ plasma solutions from healthy volunteers, which were pre-incubated with pathologic quantities of inflammatory mediators:

1. In clinical practice, all three devices work with whole blood, whose components are different from those of plasma.

2. The volume of plasma used during all tests $(500 \mathrm{ml})$ is very scant, given that examined devices work with a blood volume of about 51 and the analyzed molecules continuously regenerate in clinical setting. This scarce volume of the solution can seriously affect the results of this study.

3. The concentration of inflammatory mediators is low. This study, for example, reports IL-6 concentration of $1500 \mathrm{pg} / \mathrm{ml}$, but septic patients show much higher IL-6 levels [2, 3]. Furthermore, inflammatory mediator values in blood always change, since their kinetics are not constant.

4. All experiment duration is equal to $2 \mathrm{~h}$, which is not the actual application time of CytoSorb and oXiris, since the first one can be used for $24 \mathrm{~h}$ and the second one for a maximum of $72 \mathrm{~h}$. Adsorption treatment duration is essential in defining the saturation of each device.

Performing the experiments with a scant $500 \mathrm{ml}$ plasma solution with low and not regenerated concentrations of inflammatory mediators for only $2 \mathrm{~h}$ necessarily results in total removal of the incubated substances by the three devices. After that, there is nothing left to be adsorbed, and it is not possible to assess the saturation time of the evaluated devices, so it is not possible to understand which one effectively saturates and which one still has adsorptive capabilities.

(c) The Author(s). 2019 Open Access This article is distributed under the terms of the Creative Commons Attribution 4.0 International License (http://creativecommons.org/licenses/by/4.0/), which permits unrestricted use, distribution, and reproduction in any medium, provided you give appropriate credit to the original author(s) and the source, provide a link to the Creative Commons license, and indicate if changes were made. 
Moreover, since all three devices work in adsorbing specific molecules, a worth knowing parameter-not mentioned in this article-would be their surface area, essential to define their adsorptive capabilities and their saturation. Oxiris has a surface area of $1.5 \mathrm{~m}^{2}$, while the surface areas of Toraymyxin and CytoSorb run into thousands of square meters. This experimental setting does not point out how the three sorbents saturate, so it appears that they are all equally efficient in adsorbing their target molecules. This is probably true if you consider the only 2-h-long in vitro experiments in a small closed circuit, but it is not like that in clinical practice, where the devices work in a varying open system for a longer time and with higher and always changing target compound values.

A further analysis would be necessary to evaluate these sorbents and define the real differences among them.

\section{Response from the authors}

Benjamin Malard and John A. Kellum

We thank Dr. Feri for his interest in our paper. The intention of our manuscript was to document mechanistically the removal spectrum of different blood purification devices that may be used in the ICU according to their respective intended use. By design, this in vitro study cannot properly simulate the extremely complex patient conditions from which the intended patient population may suffer. Those limitations are clearly stated in the manuscript to avoid any misleading interpretation from a clinical practice, referring notably to "First, as an in vitro study the outcomes observed here may not be representative of the clinical setting."

Secondly, from a methodological perspective, human plasma is preferred to whole human blood because this permitted an identical setup for each experiment with the intention to interpret the observations in a relative manner. This limitation was also clearly acknowledged in the limitation section. Furthermore, each mediator selection is based on available literature on sepsis pathogenesis. Supplemental data (Table S1) clearly supports the pathological mediator concentrations selected, extrapolated to a human plasma volume of 2.51 .

We agree that the kinetics of inflammatory mediators in the blood are not constant. For that reason, the limitation section clearly states that "our data can only be used to comment on the adsorption of these mediators at these concentrations."

Dr. Feri also suggests that our methodology cannot properly compare these devices in accordance with their clinical duration and that the oXiris device may have reduced adsorptive capacities in relation to a lower surface area. To the question of the experiment duration, a 2-h session is the average treatment duration reported with the Toraymyxin cartridge in recent large-scale clinical studies [4-6]. CytoSorb may be used $6 \mathrm{~h}$ per day according its instruction for use (not $24 \mathrm{~h}$ as mentioned in the letter) [7]. The question of the experimental duration is interesting, and therefore, a calculation of clearance was proposed (Fig. 4), without any ambiguity on the respective instantaneous removal performances of each device.

To the question of the surface area, in the oXiris membrane, the microstructure and the chemical composition of the AN69 polymer offer a unique context for bulk adsorption of middle molecular weight proteins, the high water content of the hydrogel making the polymer chains easily accessible [8]. This implies that the 
surface area accessible for adsorption is considerably increased, far above the surface area that is at the blood membrane interface (i.e., $1.5 \mathrm{~m}^{2}$ for oXiris). Sakai et al. have notably proposed a model to simulate hydrogel total surface accessible for adsorption [9]. In case of oXiris, the total theoretical surface area accessible for adsorption would basically consist of approx. $17,000 \mathrm{~m}^{2}$. Of note, Nishida et al. have shown that the AN69 hydrogel membrane does not reach saturation at supra pathological quantities of HMGB-1 (seven successive pathological injection of $100 \mu \mathrm{g}$ ) [10], further illustrating this point.

The authors acknowledge that it would be interesting to determine the total amount adsorbed for each device (which was not the intent of our study) and that this preliminary work would warranty further investigations. However, our study conclusion does not provide any misleading information on how to use clinically the investigated devices and clearly provides associated limitations to the disclosed results.

Acknowledgements

Not applicable.

Funding

Not applicable.

Availability of data and materials

Not applicable.

Author's contributions

MF wrote and approved the final version of the letter.

Ethics approval and consent to participate

Not applicable.

Consent for publication

Not applicable.

Competing interests

The author declares that he has no competing interests.

\section{Publisher's Note}

Springer Nature remains neutral with regard to jurisdictional claims in published maps and institutional affiliations.

Received: 21 August 2018 Accepted: 19 November 2018

Published online: 09 January 2019

References

1. Malard B, Lambert C, Kellum JA (2018) In vitro comparison of the adsorption of inflammatory mediators by blood purification devices. Intensive Care Med Exp 6:12

2. Bozza FA, Salluh Jl, Japiassu AM, Soares M, Assis EF, Gomes RN et al (2007) Cytokine profiles as markers of disease severity in sepsis: a multiplex analysis. Crit Care 11(2):R49

3. Spittler A, Razenberger M, Kupper H, Kaul M, Hackl W, Boltz-Nitulescu G et al (2000) Relationship between interleukin-6 plasma concentration in patients with sepsis, monocyte phenotype, monocyte phagocytic properties, and cytokine production. Clin Infect Dis 31(6):1338-1342

4. Cutuli SL, Artigas A, Fumagalli R, Monti G, Ranieri VM, Ronco C, Antonelli M, The EUPHAS 2 Collaborative Group (2016) Polymyxin-B hemoperfusion in septic patients: analysis of a multicenter registry. Ann Intensive Care 6:77

5. Payen DM, Guilhot J, Launey Y, Lukaszewicz AC, Kaaki M, Veber B, Pottecher J, Joannes-Boyau O, Martin-Lefevre L, Jabaudon M, Mimoz O, Coudroy R, Ferrandière M, Kipnis E, Vela C, Chevallier S, Mallat J, Robert R, The ABDOMIX Group (2015) Early use of polymyxin B hemoperfusion in patients with septic shock due to peritonitis: a multicenter randomized control trial. Intensive Care Med 41:975-984

6. Safety and efficacy of polymyxin B hemoperfusion (PMX) for septic shock (EUPHRATES), ClinicalTrials.gov Identifier: NCT01046669

7. CytoSorb Device. Instructions for use

8. Thomas M, Moriyama K, Ledebo I (2011) AN69: evolution of the world's first high permeability membrane. Contrib Nephrol 173:119-129

9. Sakai Y, Tanzawa H (1978) Poly(methyl methacrylate) membranes. J. Appl Polymer Sci 22:1805-1815

10. Nishida O, Yumoto M, Moriyama K, Nakamura T, Kuriyama N, Hara Y, Shimomura Y, Yamada S, Miyasho T et al (2011) Adsorption is a promising mechanism for HMGB-1 removal by hemofiltration in vitro. Crit Care Med 39(12):107 